\title{
PENGARUH MODEL PEMBELAJARAN KOOPERATIF TIPE DISKURSUS MULTI REPRESENTASI (DMR) TERHADAP HASIL BELAJAR SISWA PADA MATERI POKOK SENYAWA HIDROKARBON KELAS XI MIA MAN 1 MATARAM
}

\author{
Ramli Ahmad*, I Nyoman Loka, Muti’ah \\ Program Studi Pendidikan Kimia, Universitas Mataram. Jalan Majapahit No. 62 \\ Mataram, NTB 83112, Indonesia. \\ *Coressponding Author. E-mail: ramliahmad0504@gmail.com
}

Received: 10 Februari 2020
Accepted: 15 Mei 2020 doi: 10.29303/cep.v3i1.1689
Publish: 29 Mei 2020

\begin{abstract}
Abstrak
Penelitian ini bertujuan untuk mengetahui pengaruh penerapan model pembelajaran kooperatif tipe diskursus multi representasi (DMR) terhadap hasil belajar siswa pada materi pokok senyawa hidrokarbon kelas XI MIA MAN 1 Mataram. Desain penelitian ini adalah Quasi Experimental Design dengan Pre-test Post-test Only Control Group Design. Populasi dalam penelitian ini adalah seluruh siswa kelas XI MIA 1 Mataram sebanyak 161 siswa. Sampel pada penelitian ini yaitu kelas XI MIA 3 sebagai kelas eksperimen dan kelas XI MIA 4 sebagai kelas kontrol, dengan menggunakan metode random sampling. Pada kelas eksperimen diterapkan model pembelajaran kooperatif tipe DMR sedangkan pada kelas kontrol diterapkan model pembelajaran konvensional. Data pada penelitian ini berupa hasil belajar yang dikumpulkan dengan teknik uji pre-test dan post-test. Uji hipotesis pada penelitian ini menggunakan uji-t. Hasil uji statistik uji-t $\mathrm{t}_{\text {hitung }}$ pada taraf signifikan $5 \%$ menunjukkan $t_{\text {hitung }}(3,976)>t_{\text {tabel }}(1,671)$. Nilai rata-rata siswa kelas eksperimen 75,52 lebih besar dibandingkan kelas kontrol yaitu 66,13 dan ketuntasan kalsikal pada kelas eksperimen 45,00\% lebih besar dibandingkan kelas kontrol 20,51\%. Hal tersebut menunjukan bahwa penerapan model pembelajaran kooperatif tipe DMR memberikan pengaruh yang lebih baik terhadap hasil belajar siswa pada materi pokok senyawa hidrokarbon kelas XI MIA MAN 1 Mataram.
\end{abstract}

Kata kunci: diskrusus multi representasi (DMR), pembelajaran kooperatif dan hasil belajar

The Application Infuence of Cooprative Learning Models

by Multi Representation Discourse Type (DMR) on The Student Learning Outcomes Toward The Basic Material of Hydrocarbon Compound in XI Science Class in MAN 1 Mataram

\section{Abstract}

This research aims to know the application infuence of cooprative learning models by multi representation discourse type (DMR) on the student learning outcomes toward the basic material of hydrocarbon compound in XI science class in MAN 1 Mataram. The type of this research is quasiexperimental design in the form of pre-test post-test only control group design. The population of the study involves all students fron class XI science class in MAN 1 Mataram with a total of 161. This study adjusts the random sampling method. It is taken from XI science class 3 as the experimental class and XI science class 4 as the control one. On experimental class, will be given a lesson by applying the cooprative learning models by DMR, on control class will be offered the conventional learning model. The data compiled in from of learning results gathered by unsing pre-test and posttest techniques. The hypothesis testied in this study uses the t-gain test. The result of the t-test statistic at a significant level of $5 \%$ is indicated $t_{\text {count }}(3,976)>t_{\text {table }}(1,671)$. The average result at experimental class was 75.52, the number greater than the control one with 66.13 and completeness in the experimental group $45.00 \%$ higher than control one with $20.51 \%$. The rate which is shown refers to the cooprative learning models by DMR gives better influence on student learning outcomes toward the basic material of hydrocarbon composition of grade XI class science in MAN 1 Mataram.

Keywords: multi representation discourse type (DMR), cooperative learning model and learning outcomes 


\section{PENDAHULUAN}

Pembelajaran adalah proses interaksi siswa dengan pendidik dan sumber belajar pada suatu lingkungan belajar. Pembelajaran merupakan suatu proses yang sangat penting dalam pendidikan. Tujuan pendidikan nasional untuk mengembangkan potensi peserta didik agar menjadi manusia beriman dan bertaqwa kepada Tuhan Yang Maha Esa, berakhlak mulia, sehat, berilmu, cakap, kreatif, mandiri dan menjadi warganegara yang demokratis, serta bertanggung jawab (BSNP, 2010). Pembelajaran bukan hanya diartikan sebagai sebuah proses yang dilakukan siswa untuk dapat dikatakan proses tersebut berjalan dengan baik (Ardian, 2018).

Ketercapaian dari tujuan pendidikan nasional mentukan kualitas pendidikan. Pendidikan yang berkualitas memiliki peran yang sangat penting dan strategis dalam membangun sumber daya manusia yang berkualitas. Peningkatan kualitas pendidikan harus diwujudkan dengan menjadikan suasana belajar dan proses belajar yang baik agar potensi peserta didik berkembang secara maksimal. Jika tercipta suasana dan proses belajar yang baik maka akan dapat meningkatkan mutu dan hasil belajar yang baik pula (Usman, 2018).

Hasil belajar adalah perubahanperubahan yang terjadi pada diri siswa, baik yang menyangkut aspek kognitif, afektif, dan psikomotor sebagai hasil dari kegiatan belajar (Susanto, 2013 dalam Kariani, 2014). Dimyanti dan Mudjiono (2006) juga menyebutkan hasil belajar merupakan hasil dari suatu interaksi tindak belajar dan tindak mengajar. Dari sisi guru, tindak mengajar diakhiri dengan proses evaluasi hasil belajar. Dari sisi siswa, hasil belajar merupakan berakhirnya pengajaran dari puncak proses pembelajaran.

Berdasarkan hasil observasi dan wawancara dengan guru kimia di MAN 1 Mataram, dalam proses pembelajaran guru lebih sering mengggunakan metode ceramah dan diskusi sehingga partisipasi siswa dalam pembelajaran kimia rendah. Siswa hanya memperoleh informasi dari guru tanpa mengolah informasi tersebut lebih lanjut. Akibatnya siswa menyatakan ilmu kimia itu abstrak, membosankan dan sulit untuk dipahami konsepkonsepnya, siswa hanya menghafalkan konsep ketika akan diadakan ujian, setelah itu siswa tidak mengingat kembali konsep yang diajarkan sebelumnya. Sehingga nilai rata-rata hasil belajar peserta didik cukup rendah sebagaimana disajikan dalam Tabel 1. Rendahnya hasil belajar perserta didik ditandai dari metode pembelajaran yang digunakan kurang tepat sehingga dalam proses pembelajaran guru masih kesulitan untuk mengatifkan siswa.

Tabel 1. Hasil Ulangan Tengah Semester Pelajaran Kimia Siswa Kelas X MAN 1 Mataram Tahun Ajaran 2018/2019

\begin{tabular}{cccc}
\hline Kelas & $\begin{array}{c}\text { Jumlah } \\
\text { siswa }\end{array}$ & $\begin{array}{c}\text { Jumlah } \\
\text { siswa } \\
\text { tuntas }\end{array}$ & $\begin{array}{c}\text { Nilai rata- } \\
\text { rata }\end{array}$ \\
\hline X MIA-1 & 40 & $0 \%$ & 61.80 \\
\hline X MIA-2 & 40 & $0 \%$ & 61.35 \\
\hline X MIA-3 & 40 & $0 \%$ & 60.85 \\
\hline X MIA-4 & 39 & $0 \%$ & 59.87 \\
\hline
\end{tabular}

(Sumber: Arsip Guru Kimia Kelas X MIA MAN 1 Mataram, 2019)

Metode tersebut kurang efektif, karena metode masih berpusat pada guru dan soal diskursi yang di berikan berupa soal latihan yang biasa-biasa saja tanpa di sertai dengan rangkuman meteri atau media pendukung agar menarik minat dan keaktifan siswa dalam proses pembelajaran. Hal ini terlihat dari metode yang diterapkan siswa menjadi kurang berminat, membosankan, kurang aktif dalam proses pembelajar dan sulit untuk dipahami konsepkonsepnya. Sehingga siswa hanya memperoleh informasi dari guru tanpa mengolah informasi tersebut lebih lanjut. Hal ini menyebabkan kualitas pembelajaran masih rendah yang ditandai dengan rendahnya hasil belajar yang masih jauh di bawah KKM.

Model pembelajaran kooperatif tipe DMR (diskursus multi representasi) merupakan salah satu model pembelajaran yang dapat mengaktifkan siswa di dalam kelas, karena dengan model pembelajaran ini proses belajar lebih berguna, materi pembelajaran yang diberikan oleh guru akan lebih mudah diterima oleh siswa, dan tercipta suasana pembelajaran yang menyenangkan sehingga siswa akan lebih aktif dalam kegiatan pembelajaran. Model pembelajaran kooperatif tipe DMR dapat mengemukakan pendapat dalam kelompok yang telah dibentuk, dan membuat suasana pembelajaran menjadi tidak kaku. Menurut R. Ibrahim (2003) model pembelajaran DMR bertujuan untuk membentuk karakter siswa dengan menggunakan berbagai representasi dalam proses pembelajarannya, sehingga tepat digunakan dalam proses pembelajaran. Sintak 
pembelajaran model koopertif tipe DMR meliputi persiapan, pendahuluan, pengembangan, penerapan, dan penutup (Syahyudin yang dikemukakan oleh Wahyuni. 2019).

Materi yang dipilih dalam penelitian ini adalah senyawa hidrokarbon. Pengambilan materi ini didasarkan atas pertimbangan bahwa pada materi senyawa hidrokarbon merupakan dasar materi kimia yang erat kaitannya dengan kehidupan sehari-hari, yang berguna untuk mempelajari konsep-konsep kimia lebih lanjut. Materi hidrokarbon menjadi salah satu materi kimia yang menjadi konsep prasyarat untuk konsep lain. Jika konsep hirokarbon tidak dikuasai dengan benar pada kelas XI maka pada kelas XII siswa akan kesulitan mempelajari konsep senyawa karbon dan turunannya. Materi hidrokarbon dalam proses pembelajaran, guru hanya menggunakan metode ceramah tanpa ada intraksi langsung dengan siswa. Hal ini mengakibatkan siswa sulit untuk memahami konsep dengan baik, padahal dalam materi kehidupan sehari-hari banyak sekali contoh senyawa hidrokarbon

Berdasarkan uraian tersebut perlu diadakan penelitian mengenai "pengaruh model pembelajaran kooperatif tipe diskursus multi representasi (DMR) terhadap hasil belajar siswa pada materi pokok senyawa hidrokrabon kelas XI MIA MAN 1 Mataram".

\section{METODELOGI PENELITIAN}

Penelitian ini dimulai dengan tahap persiapan penelitian dari bulan Mei 2019 dan kegiatan penelitian dilaksanakan dari tanggal 15 Juli 2019 sampai 05 Agustus 2019. Penelitian ini dilaksanakan di MAN 1 Mataram, alamat Jl. Pendidikan No. 31, Dasan Agung Baru, Kec. Selaparang, Kota Mataram.

Penelitian ini merupakan penelitian eksperimen. Penelitian eksperimen yaitu jenis penelitian yang bertujuan untuk melihat pengaruh perilaku (treatment) tertentu terhadap suatu kondisi yang terkendalikan (Sugiyono, 2013). Jenis eksperimen yang dimaksud adalah eksperimen semu (Quasi Experimental Design). Disain penelitian yang digunakan adalah Pretest dan post-test Only Control Group Design, pada desain ini terdapat dua kelompok yang ditetapkan secara random sampling. Penelitian dilakukan pada dua kelas yaitu kelas eksperimen dan kelas kontrol. Dalam penelitian ini, perlakuan yang diberikan pada kelas eksperimen berupa penerapan model pembelajaran sedangkan pada kelas kontrol menggunakan model pembelajaran konvensional (ceramah). Pada awal pelajaran siswa diberikan pre-test untuk mengukur rata-rata kamampuan kognitif sebelum kedua kelas diberi perlakuan. pada akhir pembelajaran, siswa diberikan post-test untuk mengetahui hasil belajar setelah diberikan perlakuan. Desain penelitian yang dilakukan sesuai dengan Tabel 2.

Tabel 2. Rancangan Penelitian

\begin{tabular}{lccc}
\hline Kelas & $\begin{array}{c}\text { Pre- } \\
\text { test }\end{array}$ & Perlakuan & $\begin{array}{c}\text { Post- } \\
\text { test }\end{array}$ \\
\hline Eksperimen & $\mathrm{Ya}$ & $\mathrm{X}_{1}$ & $\mathrm{Ya}$ \\
\hline Kontrol & $\mathrm{Ya}$ & $\mathrm{X}_{2}$ & $\mathrm{Ya}$ \\
\hline & & \multicolumn{2}{c}{$($ Suryabrata, 2016$)$}
\end{tabular}

Keterangan:

$\mathrm{X}_{1}=$ Pembelajaran menggunakan model

Kooperatif tipe diskursus multi representasi (DMR).

$\mathrm{X}_{2}=$ Pembelajaran menggunakan model

konvensional

Variabel bebas adalah model pembelajaran yaitu model pembelajaran kooperatif tipe diskursus multi representasi (DMR) yang diperlakukan untuk kelas eksperimen dan pembelajaran dengan model konvensional yang diperlakukan untuk kelas Kontrol. Variabel terikatnya adalah hasil belajar siswa.

Populasi yang digunakan dalam penelitian ini adalah seluruh siswa kelas XI MIA MAN 1 Mataram tahun ajaran 2018/2019, yang terdiri atas 4 kelas yakni kelas XI MIA 1 sampai kelas XI MIA 4 dengan jumlah total siswa 161 orang yang tersebar di setiap kelas. Teknik pengambilan sampel dalam penelitian ini adalah teknik random sampling, teknik pengambilan sampel yang memliki peluang atau kesempatan sama bagi setiap unsur atau anggota populasi untuk dipilih atau diambil menjadi sampel, sedangkan sampling jenuh adalah teknik penentuan sampel bila semua anggota populasi digunakan sebagai sampel (Sugiyono, 2014). Teknik random sampling dipilih karena kemampuan awal siswa keempat kelas yang digunakan sebagai populasi bersifat homogen sehingga penelitian menggunakan eksperimen semu (quasi eksperimen) yang kelasnya diacak.

Penelitian ini menggunakan instrumen tes hasil belajar kimia dalam bentuk pilihan ganda. Instrumen yang disusun terlebih dahulu diuji tingkat validitasnya dengan validitas ahli 
menggunakan Aiken's V dan validitas butir soal menggunakan rumus korelasi point biseral. Untuk menguji reliabilitas instrumen digunakan rumus rumus K-R.20. Uji hipotesis dalam penelitian ini menggunakan uji normalitas, uji homogenitas dan uji $\mathrm{N}$-gain $\mathrm{t}$ dikarenakan pengujian yang dilakukan bukan terhadap nilai rata-rata tetapi terhadap selisih atau perbedaan nilai rata-rata (Arikunto, 2013).

\section{HASIL DAN PEMBAHASAN}

Tujuan penelitian ini adalah untuk mengetahui pengaruh penerapan model pembelajaran kooperatife tipe diskursus multi representasi (DMR) terhadap hasil belajar siswa pada materi pokok senyawa hidrokrabon kelas XI MIA MAN 1 Mataram setelah melalui proses pembelajaran. Pengunaan model pembelajaran kooperatife tipe diskursus multi representasi (DMR) terhadap hasil belajar siswa pada materi pokok senyawa hidrokrabon di yakini dapat meningkatkan hasil belajar siswa dalam ranah kognitif pada materi hidrokarbon. Model pembelajaran yang diterapkan di kelas eksperimen adalah kooperatife tipe diskursus multi representasi (DMR) dan model pembelajaran yang diterapkan di kelas kontrol adalah model pembelajaran konvensional. Masing-masing kelas diajar dengan materi yang sama yaitu senyawa hidrokarbon yang berlangsung selama 6 kali pertemuan.

Hasil belajar kimia yang diperoleh dari penelitian ini adalah hasil belajar pada ranah kognitif yang didapatkan dari hasil pre-test dan post-test. Berdasarkan hasil perhitungan nilai pre-test dan post-test siswa didapatkan perbedaan nilai hasil belajar kimia kelas eksperimen dan kelas kontrol sebagaimana disajikan pada Gambar 1.

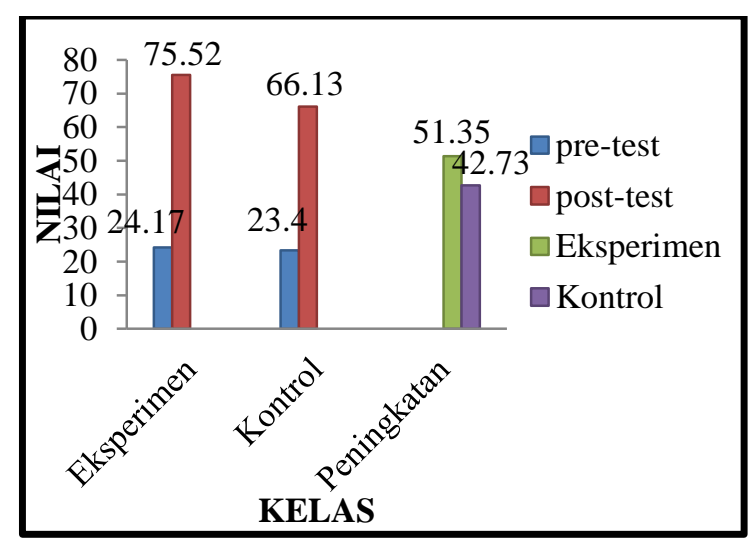

Gambar 1. Nilai rata-rata pre-test - post-test kelas eksperimen dan kelas kontrol
Berdasarkan peningkatan rata-rata yang diperoleh maka dapat diketahui bahwa hasil belajar kelas eksperimen lebih tinggi dari pada kelas kontrol. Hal ini disebabkan oleh beberapa faktor yang menguatkan proses pembelajaran kooperatif tipe DMR dalam penelitian ini. Adapun faktor tersebut adalah mengembangkan cara belajar siswa dengan menemukan sendiri dan saling mengajukan pendapat antar siswa sehingga melibatkan siswa untuk berperan aktif dalam setiap tahapan proses pembelajaran. Selain itu dengan adanya penggunaan media lembar kerja perserta didik (LKPD) dapat meningkatkan minat dan aktifitas belajar siswa, karena dalam pemanfaatan media tersebut berisikan materi yang singkat, padat dan jelas sehingga memudahkan siswa untuk memahami materi pelajaran. Hal ini menunjukkan bahwa perlakuan yang diberikan pada kelas eksperimen berpengaruh lebih baik terhadap hasil belajar siswa.

Hal ini diperkuat dengan data yang di peroleh dari hasil uji N-Gain. Perbandingan ratarata hasil hitung skor gain pada kelas eksperimen dan kelas kontrol dapat dilihat pada Gambar 2.

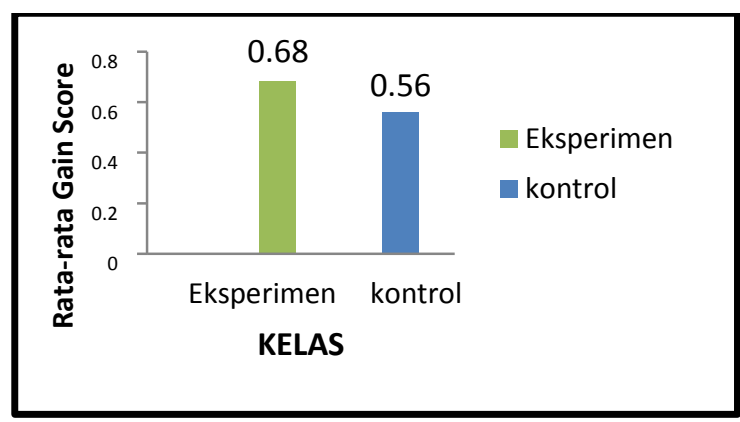

Gambar 2. Perbandingan nilai N-Gain kelas eksperimen dan kelas kontrol

Pencapaian peningkatan hasil belajar pada kelas eksperimen cukup bagus dari pada kelas kontrol. Rendahnya hasil belajar kimia siswa pada kelas kontrol dengan model pembelajaran konvensional disebabkan beberapa alasan diantaranya, 1) penggunaan metode pembelajaran yang tidak tepat. Penggunaan metode ceramah yang menjadi dominan dalam pembelajaran di dalam kelas sehingga hanya berpusat pada guru, hal ini akan membuat siswa jenuh karena hanya mendengarkan saja sehingga membuat siswa tidak tertarik dengan materi yang di ajarkan. Hal tersebut membuat siswa menjadi pasif di dalam kelas, 2) siswa pada kelas kontrol tidak kondusif, kelasnya ribut sehingga menyebabkan guru kewalahan dalam 


\section{Chemistry Education Practice,3 (1), 2020 - 45}

Ahmad, Loka, Muti'ah

menyampaikan materi secara optimal, 3) kurangnya pemanfaatan media pembelajaran sehingga siswa kurang termotivasi dalam mempelajari ilmu kimia.

Perolehan nilai rata-rata $N$-gain pada kelas eksperimen lebih tinggi dari rata-rata nilai $\mathrm{N}$-gain kelas kontrol, maka dapat disimpulkan bahwa terjadi perbedaan hasil belajar akibat perbedaan perlakuan yang diberikan pada kedua sampel, dimana kelas eksperimen yang diberikan perlakukan dengan model pembelajaran koopratif tipe diskursus multi representasi (DMR) memberikan pengaruh yang lebih baik terhadap hasil belajar jika dibandingkan dengan kelas kontrol yang diberikan perlakuan dengan model konvensional.

Berdasarkan data dari perhitungan menggunakan Uji-t diperoleh $t_{\text {hitung }}=3,976$, sedangkan $t_{\text {tabel }}=1,671$. Nilai $t_{\text {hitung }}$ dikonfirmasikan dengan nilai $t_{\text {tabel }}$ hasil yang diperoleh adalah $t_{\text {hitung }}(3,976)>t_{\text {tabel }}(1,671)$ sehingga Ho ditolak dan Ha diterima, sedangkan hasil nilai rata-rata siswa kelas eksperimen 75,52 lebih besar dibanding kelas kontrol yaitu 66,13 dan ketuntasan kalsikal pada kelas eksperiman $45,00 \%$ lebih besar dibandingkan kelas kontrol $20,51 \%$. Sehingga dapat disimpulkan bahwa penerapan model pembelajaran kooperatif tipe diskursus multi representasi (DMR) memberikan pengaruh yang lebih baik terhadap hasil belajar pada materi pokok senyawa hidrokarbon kelas XI MIA MAN 1 Mataram. Hasil penelitian ini sejalan dengan penelitian Dwi Sulistyowati (2013). Hasil penelitian tersebut memiliki hasil $t_{\text {hitung }}>t_{\text {tabel}}$, sehingga penerapan model pembelajaran kooperatif tipe diskursus multi representasi (DMR) memberikan pengaruh yang lebih baik terhadap hasil belajar siswa.

Banyaknya kelebihan dari model pembelajaran kooperatif tipe diskursus multi representasi (DMR) juga tidak terlepas dari kekurangan selama proses penelitian. Beberapa permasalahan yang muncul diantaranya : 1) masih ditemukan beberapa siswa yang masih belum berpartisipasi dalam proses pembelajaran seperti siswa sulit untuk berdiskusi dengan teman kelompok hal ini terlihat dari beberapa siswa yang masih bingung saat mengerjakan soal, 2) ketika siswa dalam menyampaikan kesimpulan masih belum baik sehingga diperlukan bantuan guru untuk memperbaiki.

\section{KESIMPULAN}

Berdasarkan data hasil penelitian dan pembahasan, dapat disimpulkan bahwa penerapan model pembelajaran kooperatif tipe diskursus multi representasi (DMR) memberikan pengaruh yang lebih baik pada hasil belajar materi pokok senyawa hidrokarbon siswa kelas XI MIA MAN 1 Mataram.

\section{SARAN}

Berdasarkan penelitian yang sudah dilakukan, peneliti mengajukan saran, kepada mahasiswa (calon guru kimia) agar dapat melakukan penelitian lebih lanjut dengan menggunakan model pembelajaran kooperatif tipe diskursus multi representasi (DMR) pada materi yang lain dan tidak hanya mencakup ranah kognitif, melainkan dapat mencakup ranah afektif dan psikomotorik maupun tingkat berpikir tingkat tinggi dengan memperhatikan karakter siswa dan faktor-faktor lain yang berpengaruh terhadap prestasi belajar siswa sehingga dapat lebih menyempurnakan penelitian sebelumnya.

\section{DAFTAR PUSTAKA}

Arikunto, S. 2013. Dasar-Dasar Evaluasi Pendidikan Edisi 2. Jakarta : Bumi Aksara.

Badan Standar Nasional Pendidikan 2010. Paradigma Pendidikan Nasional Di Abad-21. Jakarta : BSNP.

Dimyati dan Mudjiono. 2006. Belajar dan Pembelajaran. Jakarta : Rineka Cipta.

Gunwan, L.A. 2018. Pengaruh model pembelajaran koopertatif tipe team assisted individualization (TAI) berbantuan studi card terhadap hasil belajar kimia. Chemistry Education Practice, 2(2) : 1-7

Kariani, N. K., Putra, D. K. N. S., dan Ardana, I. K. 2014. Model Problem Based Learning Menggunakan Metode Probing-Prompting Berpengaruh Terhadap Hasil Belajar IPA Siswa. Jurnal Mimbar PGSD Universitas Pendidikan Ganesha. 2 (1) : 1-10.

R, Ibrahim. 2003. Perencanaan Pengajaran. Jakarta : PT Rinek Cipta.

sugiyono. 2013. Metode Penelitian Pendidikan Pendekatan Kuantitatif, Kualitatif, dan $R \& D$. Bandung: Alfabeta. 
Chemistry Education Practice,3 (1), 2020 - 46

Ahmad, Loka, Muti'ah

2014. Metode penelitian Kualitatif,

Kuantitatif dan $R \& D$. Bandung:

Alfabeta.

Sulistyowati, D. 2017. "Pengaruh Penerapan Model Pembelajaran Diskursus Multy Reprecentacy (DMR) Terhadap Motivasi, Keaktifan Dan Hasil Belajar Siswa Pada Materi Himpunan Kelas VII Mts Ma'murotul Husna Kediri Tahun Ajaran 2016/2017". SKRIPSI FKIP Universitas Nusantara PGRI Kediri.

Suryabrata, S. 2012. Psikologi Pendidikan. Jakarta: Rajawali Pers.

Usman. 2018."Pengaruh Penerapan Model Pembelajaran Berbasis Masalah Dengan Metode Probing Prompting Terhadap Hasil Belajar Kimia Materi Pokok Sistem Koloid Pada Siswa Kelas Xi Sman 1 Kuripan Tahun Ajaran 2017/2018". SKRIPSI FKIP Universitas Mataram.

Wahyuni. 2019. "Pengaruh Model Pembelajaran Diskursus Multi Representasi (DMR) Ditinjau Dari Kecerdasan Majemuk Terhadap Kemampuan Komunikasi Matematis Peserta Didik". SKRIPSI UIN Raden Intan Lampung. 